\title{
O enfermeiro na realização do exame de Papanicolau: obstáculos e a percepção da
}

\section{mulher}

The nurse in the performance of the Papanicolau exam: obstacles and the perception of women

La enfermera en la realización del examen Papanicolau: obstáculos y percepción de las mujeres

\section{Resumo}

Diante do exposto, este estudo tem como objetivo compreender a finalidade do enfermeiro no teste de Papanicolau: obstáculo e percepção da mulher, de modo a alcançar e demonstrar a importância do exame do Papanicolau. Metodo: Revisão Integrativa realiza da no mês de setembro de 2021 nas bases de dados on-line BDENF e LILACS no periodo de 2008 a 2021. Para a pesquisa, utizou-se o descritor "Enfermeiro" e "Exame Papanicolau" com a palavra-chave "Percepção", utilizando o boleando "AND" entre as palavras. Foram encontrados 115 artigos, 54 do BDENF e 61 do Lilacs, sendo selecionados 12 e excluidos 103, com a associação dos descritores. Resultados: os resultados apontam que são muitos os fatores que contribuem para a não adesão das mulheres ao exame Papanicolau, como por exemplo; receio da exposição corporal, profissional do sexo masculino, não conhecimento da gravidade do câncer e a importancia do rastreio, dentre outros fatores, alem de evidenciar que o enfermeiro pode e deve se fazer presente na ruptura de tais paradigmas. Concui-se por tanto que para que exista adesão das mulheres ao exame é importante estratégia e busca ativa, bem como fortalecimento de vinculo e adoção de medidas como educação em saúde para a construção dos saberes necessarios a mulher.

Palavras-chave: Enfermeiros; Exame de Papanicolau; Percepção.

\begin{abstract}
Given the above, this study aims to understand the purpose of nurses in the Pap smear: obstacle and women's perception, in order to achieve and demonstrate the importance of the Pap smear. Method: Integrative review carried out in September 2021 in the online databases BDENF and LILACS in the period from 2008 to 2021. For the research, we used the descriptors "Nurse" and "Pap examination" with the word- "Perception" key, using the "AND" between the words. 115 articles were found, 54 from BDENF and 61 from Lilacs, 12 were selected and 103 were excluded, with the association of descriptors. Results: the results show that there are many factors that contribute to the non-adherence of women to the Pap smear, for example; fear of bodily exposure, male professional, lack of knowledge of the severity of cancer and the importance of screening, among other factors, in addition to showing that
\end{abstract}


nurses can and should be present in the rupture of such paradigms. It is concluded, therefore, that for women to adhere to the exam, an important strategy and an active search is important, as well as strengthening the bond and adopting measures such as health education for the construction of the necessary knowledge for women.

Keywords: Nurses; Pap smear test; Perception.

\section{Resumen}

Dado lo anterior, este estudio tiene como objetivo comprender el propósito de las enfermeras en la prueba de Papanicolaou: obstáculo y percepción de las mujeres, para lograr y demostrar la importancia de la prueba de Papanicolaou. Método: Revisión integrativa realizada en septiembre de 2021 en las bases de datos en línea BDENF y LILACS en el período de 2008 a 2021. Para la investigación se utilizaron los descriptores "Enfermera" y "Papanicolaou" con la palabra- clave "Percepción", utilizando el "Y" entre las palabras. Se encontraron 115 artículos, 54 de BDENF y 61 de Lilacs, se seleccionaron 12 y se excluyeron 103, con la asociación de descriptores. Resultados: los resultados muestran que son muchos los factores que contribuyen a la no adherencia de las mujeres al Papanicolaou, por ejemplo; miedo a la exposición corporal, profesional masculino, desconocimiento de la gravedad del cáncer y la importancia del cribado, entre otros factores, además de mostrar que el enfermero puede y debe estar presente en la ruptura de tales paradigmas. Se concluye, por tanto, que para que las mujeres se adhieran al examen es importante una estrategia importante y una búsqueda activa, así como fortalecer el vínculo y adoptar medidas como la educación en salud para la construcción de los conocimientos necesarios para las mujeres.

Palabras clave: Enfermeras; Prueba de Papanicolaou; Percepción.

\section{Introdução}

O câncer do colo uterino traça o seu desenvolvimento como sendo o quarto tipo de câncer / neoplasia mais comum entre o sexo feminino, representando um potente problema de saúde pública, os dados apontam que no ano de 2015 ocorreram em média 270 mil mortes por esse tipo de câncer, sendo $90 \%$ dos casos ocorridos em países com desenvolvimento baixo e médio. As projeções globais para o recorte temporal de 2015- 2030 apontam ainda um crescimento da mortalidade em 22\% pelo câncer de colo uterino, com uma média de $27 \%$ de mortes em países subdesenvolvidos e $1 \%$ em países desenvolvidos (Feitoza, et. al., 2015).

Especificamente no Brasil é contado como um problema na saúde pública, onde a taxa de prevalência e mortalidade é mais alta principalmente em mulheres que apresentam baixa situação socioeconômica (Silveira, 2016).

Segundo o instituto nacional do câncer (Inca, 2020 p. 38) "O número de casos novos de câncer do colo do útero esperados para o Brasil, para cada ano do triênio 2020- 2022 serão de 16.590, com um risco estimado de 1.543 casos a cada 100 mil mulheres". Mesmo com a evidencia apresentada em números e percentuais, a história fisiopatológica do câncer do colo de útero já foi apresentada e bem definida, onde a infecção previa pelo vírus HPV, possui importante papel no desenvolvimento da neoplasia e aspectos secundários, como tabagismo e o uso de contraceptivos orais também são considerados como fatores de risco.

Para haver o controle e a prevenção do câncer do colo uterino se da através da detecção prévia das lesões préinvasivas onde é executado por meio do exame de preventivo denominado como Papanicolau, este vem sendo utilizado há mais de 50 décadas (Smieskii; Dullius \& Venazzi, 2018).

O exame do Papanicolau é um dos principais meios para identificar as lesões do colo do útero. Contudo, as mulheres deixam de realiza-lo por medo, falta de conhecimento, vergonha e por várias vezes não haver a confiança necessária no enfermeiro, deixando notório, a necessidade de haver um maior entendimento desse profissional, através da sua execução nessa conjuntura (Villani, 2012).

Obtendo o diagnóstico precoce da doença tem-se a probabilidade de lograr um tratamento congruente com menos danos aos pacientes, podendo chegar ate $100 \%$ da cura esperada (Santos, Rocha \& Cunha, 2014).

Diante a problemática exposta, observa-se a preocupação com critérios que venham a prevenir o desenvolvimento desse câncer, o Ministério da Saúde (MS) preconiza que ocorra o rastreamento de todas as mulheres com vida sexual ativa e com idade entre 25 e 64 anos, ocorrendo esses rastreamentos dentro de uma periodicidade previamente definida. Para além da 
ação de rastreamento, o Brasil possui na atualidade a vacina contra o vírus HPV, estando esta disponível para meninas e meninos (Gonçalves, et. al., 2020).

Diante do exposto, este estudo tem como objetivo compreender a finalidade do enfermeiro no teste de Papanicolau: obstáculo e percepção da mulher, de modo a alcançar e demonstrar a importância do exame do Papanicolau.

\section{Metodologia}

Foi realizada uma pesquisa de revisão integrativa de literatura, para identificar e descrever sobre o enfermeiro na realização do exame de Papanicolau: Obstáculos e a percepção da mulher.

Trata-se de uma revisão integrativa de literatura realizada através de um levantamento bibliográfico, considerado um método que visa sintetizar os resultados obtidos na pesquisa de determinado tema ou questão de forma ordenada, sistemática e holística (Galvão \& Pereira, 2014).

Abaixo está uma lista de artigos encontrados. Os resultados coletados estão apresentados no Quadro 1, que corresponde às etapas de exclusão e inclusão dos artigos nas seguintes bases de dados: Literatura Latino-Americana e do Caribe em Ciências da Saúde (LILACS) e Base de Dados de Enfermagem (BDENF).

Figura 1: Fluxograma de recuperação dos artigos.

\section{TOTAL DE ESTUDOS IDENTIFICADOS \\ LILACS \\ BDENF}

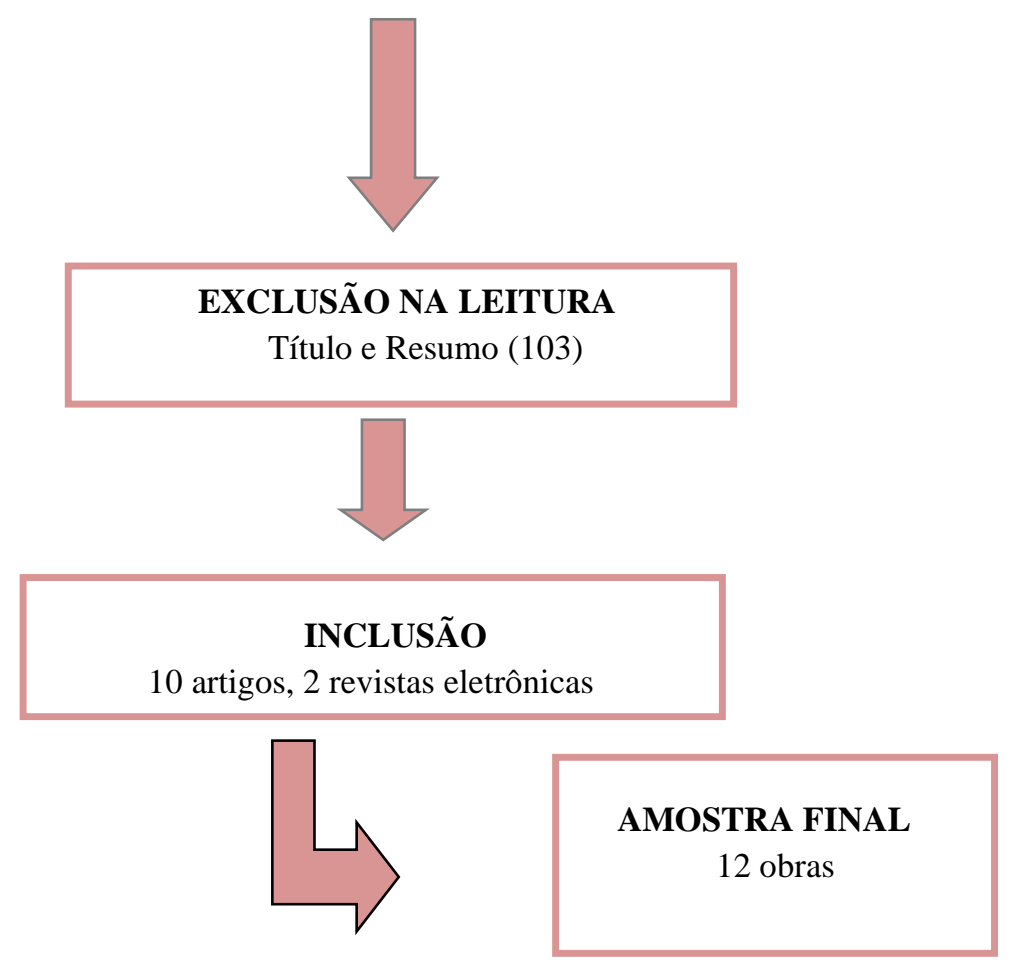

Fonte: Autores.

A extração de dados é realizada por meio de pesquisa bibliográfica de diversos trabalhos que enfatizam o objeto de pesquisa. Em suma, após a coleta de dados, a análise começa com a pesquisa narrativa, pois proporciona aos investigadores uma conexão direta e positiva com a base. 
Quadro 1: Descrição dos estudos selecionados referentes aos títulos, ano, revista, objetivo, metodologia e resultado.

\begin{tabular}{|c|c|c|c|c|c|}
\hline Titulo & Ano & Revista & Objetivo & Metodologia & Resultado \\
\hline $\begin{array}{l}\text { Adesão das } \\
\text { mulheres ao } \\
\text { exame } \\
\text { citológico do } \\
\text { colo uterino na } \\
\text { atenção básica. }\end{array}$ & 2016 & $\begin{array}{l}\text { Rev. enferm } \\
\text { UFPE on } \\
\text { line. }\end{array}$ & $\begin{array}{c}\text { Avaliar o perfil } \\
\text { sociodemográfico e a } \\
\text { adesão das mulheres ao } \\
\text { exame citológico do colo } \\
\text { uterino na Atenção } \\
\text { Básica. }\end{array}$ & $\begin{array}{c}\text { Estudo exploratório } \\
\text { descritivo, de abordagem } \\
\text { quantitativa, desenvolvido } \\
\text { em } 20 \text { Unidades de Saúde } \\
\text { da Família de João Pessoa } \\
\text { (PB), Brasil, com } 384 \\
\text { mulheres, que procuraram } \\
\text { atendimento nesses } \\
\text { serviços de saúde. }\end{array}$ & $\begin{array}{l}\text { Vergonha, ansiedade, prazo para } \\
\text { recebimento do resultado do exame, } \\
\text { foram os principais fatores que } \\
\text { dificultam a realização do citológico. }\end{array}$ \\
\hline $\begin{array}{l}\text { Percepção de } \\
\text { usuárias acerca } \\
\text { do exame de } \\
\text { detecção } \\
\text { precoce do } \\
\text { câncer de colo } \\
\text { uterino }\end{array}$ & 2016 & $\begin{array}{l}\text { Revista } \\
\text { Cogitare }\end{array}$ & $\begin{array}{l}\text { Objetivou-se descrever a } \\
\text { percepção de usuárias } \\
\text { acerca do exame de } \\
\text { detecção precoce do } \\
\text { câncer de colo uterino. } \\
\text { Trata-se de pesquisa } \\
\text { descritiva desenvolvida } \\
\text { em cinco Unidades } \\
\text { Básicas de Saúde de um } \\
\text { município do interior do } \\
\text { estado do Ceará, de } \\
\text { janeiro a abril de } 2015 \text {. }\end{array}$ & $\begin{array}{l}\text { Trata-se de pesquisa } \\
\text { descritiva de caráter } \\
\text { qualitativo, desenvolvida } \\
\text { nas Unidades Básicas de } \\
\text { Saúde (UBS) de um } \\
\text { município do interior do } \\
\text { Estado do Ceará. }\end{array}$ & $\begin{array}{l}\text { Os resultados obtidos foram } \\
\text { organizados e agrupados em quatro } \\
\text { categorias pré-estabelecidas. A } \\
\text { primeira categoria diz respeito ao } \\
\text { significado que o exame preventivo } \\
\text { tem para a usuária, a segunda } \\
\text { apresenta a frequência com a qual } \\
\text { essas mulheres realizam o exame, a } \\
\text { terceira está relacionada aos } \\
\text { sentimentos vivenciados durante a } \\
\text { realização do mesmo e a quarta } \\
\text { aborda os possíveis motivos que } \\
\text { poderiam levar a mulher a se recusar } \\
\text { a fazer o exame. }\end{array}$ \\
\hline $\begin{array}{l}\text { Percepção e } \\
\text { adesão das } \\
\text { mulheres quanto } \\
\text { ao exame } \\
\text { citopatológico. }\end{array}$ & 2018 & $\begin{array}{l}\text { Revista } \\
\text { Nursing }\end{array}$ & $\begin{array}{c}\text { Conhecer a concepção } \\
\text { das mulheres sobre o } \\
\text { exame Papanicolau, e os } \\
\text { fatores relacionados a não } \\
\text { adesão ao exame } \\
\text { preventivo de } \\
\text { Papanicolau. }\end{array}$ & $\begin{array}{l}\text { Trata-se de um estudo } \\
\text { transversal quantitativo, } \\
\text { retrospectivo onde foram } \\
\text { aplicados questionários } \\
\text { com mulheres que } \\
\text { procuram a Unidade Saúde } \\
\text { da Família para prevenção } \\
\text { câncer do colo útero, no } \\
\text { período de junho a } \\
\text { agosto/2016. }\end{array}$ & $\begin{array}{l}\text { As mulheres relatam sentir } \\
\text { constrangimento frente ao } \\
\text { profissional do sexo masculino por } \\
\text { exposição do corpo, e apenas } 20 \% \text { de } \\
80 \% \text { aceitaria realizar o procedimento } \\
\text { com profissional enfermeiro. }\end{array}$ \\
\hline $\begin{array}{l}\text { Atuação do } \\
\text { enfermeiro da } \\
\text { estratégia da } \\
\text { saúde da } \\
\text { família no } \\
\text { manejo da } \\
\text { mulher com } \\
\text { resultado de } \\
\text { colpocitologia } \\
\text { alterado }\end{array}$ & 2020 & $\begin{array}{l}\text { Research, } \\
\text { Society and } \\
\text { Development }\end{array}$ & $\begin{array}{l}\text { Analisar com base na } \\
\text { literatura atuação do } \\
\text { enfermeiro da estratégia } \\
\text { da saúde da } \\
\text { família no manejo da } \\
\text { mulher com resultado } \\
\text { de exames } \\
\text { colpocitológicos } \\
\text { alterado. }\end{array}$ & $\begin{array}{l}\text { Trata-se de uma revisão } \\
\text { integrativa da literatura, } \\
\text { com abordagem } \\
\text { qualitativa }\end{array}$ & $\begin{array}{l}\text { Apontam sistema de saúde falho em } \\
\text { relação a demora no seguimento de } \\
\text { consultas } \\
\text { importantes para o tratamento, além } \\
\text { da adesão e percepção de mulheres } \\
\text { sobre o exame } \\
\text { Papanicolaou está ligada a } \\
\text { múltiplos fatores que impedem o } \\
\text { controle do câncer do colo de útero } \\
\text { e a importância do enfermeiro nas } \\
\text { ações de controle do câncer } \\
\text { cervical para a diminuição da } \\
\text { incidência da neoplasia }\end{array}$ \\
\hline $\begin{array}{l}\text { Principais } \\
\text { dificuldades } \\
\text { para a realização } \\
\text { do exame } \\
\text { papanicolau em } \\
\text { mulheres } \\
\text { atendidas em } \\
\text { uma unidade } \\
\text { básica de saúde } \\
\text { no bairro } \\
\text { Jaderlândia, } \\
\text { Ananindeua, } \\
\text { estado do Pará }\end{array}$ & 2020 & $\begin{array}{l}\text { Brazilizan } \\
\text { journal of } \\
\text { development }\end{array}$ & $\begin{array}{l}\text { Identificar as principais } \\
\text { causas de mulheres entre } \\
25 \text { a } 65 \text { anos não } \\
\text { realizarem o exame } \\
\text { preventivo do câncer de } \\
\quad \text { colo útero }\end{array}$ & $\begin{array}{l}\text { Trata-se de um estudo } \\
\text { descritivo, exploratório } \\
\text { com abordagem qualitativa }\end{array}$ & $\begin{array}{l}\text { Falhas do gerenciamento da UBS, } \\
\text { gestão de materiais e a ausência do } \\
\text { profissional de saúde, as dificuldades } \\
\text { que levam as mulheres a } \\
\text { desacreditarem no exame são: demora } \\
\text { no resultado do exame }\end{array}$ \\
\hline
\end{tabular}




\begin{tabular}{|c|c|c|c|c|c|}
\hline $\begin{array}{l}\text { Prevenção } \\
\text { do câncer de } \\
\text { colo de } \\
\text { útero: a } \\
\text { atuação do } \\
\text { profissional } \\
\text { enfermeiro } \\
\text { nas unidades } \\
\text { básicas de } \\
\text { saúde }\end{array}$ & 2020 & $\begin{array}{l}\text { Revista } \\
\text { Científica } \\
\text { FacMais }\end{array}$ & $\begin{array}{c}\text { Foi analisar a importância } \\
\text { do enfermeiro na } \\
\text { prevenção do câncer de } \\
\text { colo do útero e sua } \\
\text { atuação profissional no } \\
\text { contexto da estratégia de } \\
\text { saúde da família }\end{array}$ & $\begin{array}{l}\text { Foi realizada uma revisão } \\
\text { bibliográfica integrativa } \\
\text { sistemática com caráter } \\
\text { descritivo exploratório em } \\
\text { base de dados virtuais }\end{array}$ & $\begin{array}{c}\text { O profissional enfermeiro é o } \\
\text { principal responsável dentro da APS } \\
\text { na prevenção desta doença por ser } \\
\text { capaz de analisar as dificuldades } \\
\text { encontradas para a realização do } \\
\text { exame citopatológico. }\end{array}$ \\
\hline $\begin{array}{l}\text { Rastreamento do } \\
\text { câncer do colo } \\
\text { do útero no } \\
\text { Estado do } \\
\text { Maranhão, } \\
\text { Brasil. }\end{array}$ & 2014 & $\begin{array}{l}\text { Ciência \& } \\
\text { Saúde } \\
\text { Coletiva }\end{array}$ & $\begin{array}{l}\text { O objetivo do estudo foi } \\
\text { analisar o rastreamento do } \\
\text { câncer do colo do útero no } \\
\text { Maranhão, através dos } \\
\text { dados do Sistema de } \\
\text { Informação do Câncer do } \\
\text { Colo do Útero (Siscolo) }\end{array}$ & $\begin{array}{l}\text { Realizou-se estudo } \\
\text { retrospectivo observacional } \\
\text { com dados dos exames } \\
\text { citopatológicos coletados } \\
\text { nas Unidades Básicas de } \\
\text { Saúde (UBS) e cadastrados } \\
\text { no Siscolo do Estado do } \\
\text { Maranhão, referente ao } \\
\text { período de janeiro a } \\
\text { dezembro de } 2011 \text {. }\end{array}$ & $\begin{array}{l}\text { A caracterização sociodemográfica } \\
\text { com dados de etnia/raça, estado civil } \\
\text { e ocupação não foram possíveis } \\
\text { analisar em virtude da não } \\
\text { transferência destas informações ao } \\
\text { Siscolo pelas UBS maranhenses. }\end{array}$ \\
\hline $\begin{array}{l}\text { Mulheres } \\
\text { portadoras de } \\
\text { câncer de colo } \\
\text { de útero: a } \\
\text { percepção da } \\
\text { assistência de } \\
\text { enfermagem. }\end{array}$ & 2014 & $\begin{array}{l}\text { Revista } \\
\text { Recom }\end{array}$ & $\begin{array}{l}\text { Conhecer a percepção da } \\
\text { mulher acometida pelo } \\
\text { câncer de colo uterino } \\
\text { sobre a assistência de } \\
\text { enfermagem no itinerário } \\
\text { do tratamento. }\end{array}$ & $\begin{array}{l}\text { A pesquisa de natureza } \\
\text { qualitativa permite a livre } \\
\text { expressão dos sujeitos } \\
\text { sobre suas vivências e } \\
\text { experiência acerca de } \\
\text { determinada temática } \\
\text { possibilita a análise de } \\
\text { questões particulares e } \\
\text { subjetivas além de } \\
\text { favorecer a compreensão } \\
\text { dos significados das } \\
\text { relações humanas. Deste } \\
\text { modo, optou-se por esta } \\
\text { metodologia para a } \\
\text { realização deste estudo }\end{array}$ & $\begin{array}{l}\text { Considera-se que o papel do } \\
\text { enfermeiro está muito além da } \\
\text { realização de cuidados as mulheres } \\
\text { em sua fase de internação ou } \\
\text { tratamento ambulatorial, pois esse faz } \\
\text { parte da rede de apoio e confiança } \\
\text { para tornar o recebimento do } \\
\text { diagnóstico do câncer de colo de útero } \\
\text { uma realidade menos traumática, } \\
\text { informando sua possibilidade de } \\
\text { tratamento, diminuindo o estigma de } \\
\text { que o câncer é uma doença sem cura e } \\
\text { que levará a todos que recebem esse } \\
\text { diagnóstico. }\end{array}$ \\
\hline $\begin{array}{l}\text { Conhecimento e } \\
\text { motivações das } \\
\text { mulheres acerca } \\
\text { do exame de } \\
\text { papanicolau : } \\
\text { subsídios para a } \\
\text { para a prática de } \\
\text { enfermagem. }\end{array}$ & 2010 & Rev. Rene & $\begin{array}{c}\text { Este estudo objetiva } \\
\text { caracterizar o perfil } \\
\text { sociodemográfi co das } \\
\text { mulheres atendidas numa } \\
\text { unidade de saúde; e } \\
\text { investigar o conhecimento } \\
\text { e a motivação que as } \\
\text { levaram a se submeterem } \\
\text { ao exame de Papanicolau. }\end{array}$ & $\begin{array}{l}\text { Trata-se de uma pesquisa } \\
\text { do tipo exploratório } \\
\text { descritiva, de natureza } \\
\text { qualitativa, realizada num } \\
\text { Centro de Saúde de } \\
\text { Atenção Primária, na } \\
\text { cidade de Paracuru - } \\
\text { Ceará. }\end{array}$ & $\begin{array}{l}\text { Atitudes citadas pelos profissionais } \\
\text { foram efetivas e humanizadoras e se } \\
\text { apresentam como sugestões para } \\
\text { profissionais que atuam nessa área. }\end{array}$ \\
\hline $\begin{array}{l}\text { Prevenção do } \\
\text { câncer de colo } \\
\text { de útero: a } \\
\text { atuação do } \\
\text { profissional } \\
\text { enfermeiro nas } \\
\text { unidades básicas } \\
\text { de saúde }\end{array}$ & 2017 & $\begin{array}{c}\text { Rev. } \\
\text { Cientifica }\end{array}$ & $\begin{array}{l}\text { Analisar a importância do } \\
\text { enfermeiro na prevenção } \\
\text { do CCU e sua atuação } \\
\text { profissional no contexto } \\
\text { da estratégia de saúde da } \\
\text { família. }\end{array}$ & $\begin{array}{c}\text { O presente estudo tem } \\
\text { caráter descritivo } \\
\text { exploratório, adotado como } \\
\text { método a revisão } \\
\text { bibliográfica integrativa } \\
\text { sistemática em base de } \\
\text { dados virtuais. Para } \\
\text { levantamento dos artigos } \\
\text { foi realizada busca online } \\
\text { na Biblioteca Virtual de } \\
\text { Saúde }\end{array}$ & $\begin{array}{l}\text { Fica evidente que o profissional } \\
\text { enfermeiro é o principal responsável } \\
\text { dentro da atenção primária, por ser } \\
\text { capaz de analisar as dificuldades } \\
\text { encontradas para a realização do } \\
\text { exame citopatológico, dessa forma ele } \\
\text { pode buscar soluções adequadas } \\
\text { através de uma postura crítico- } \\
\text { reflexiva para a busca de uma } \\
\text { assistência mais humanizada }\end{array}$ \\
\hline $\begin{array}{l}\text { Perfil das } \\
\text { mulheres que } \\
\text { realizam o } \\
\text { exame } \\
\text { Papanicolau em } \\
\text { uma estratégia } \\
\text { de saúde da } \\
\text { família }\end{array}$ & 2016 & $\begin{array}{l}\text { Journal of } \\
\text { nursing } \\
\text { health }\end{array}$ & $\begin{array}{l}\text { Conhecer o perfil das } \\
\text { mulheres que realizaram o } \\
\text { exame preventivo } \\
\text { papanicolau em Primavera } \\
\text { do Leste, Mato-Grosso. }\end{array}$ & $\begin{array}{c}\text { O estudo foi realizado } \\
\text { através da aplicação de } \\
\text { questionário } \\
\text { semiestruturado, sendo } \\
\text { aprovado pelo Comitê de } \\
\text { Ética em Pesquisa, } \\
\text { protocolo 515/70. }\end{array}$ & $\begin{array}{c}\text { a média de idade }=41 \text { anos, } 36 \% \\
\text { possuem ensino médio completo. A } \\
\text { maioria trabalha em casa. Média de } 2 \\
\text { filhos. Realizaram o exame } \\
\text { principalmente por prevenção e } \\
\text { orientação médica. O profissional que } \\
\text { mais orientou sobre o HPV foram os } \\
\text { agentes comunitários de saúde. Não } \\
\text { gostam do exame preventivo por } \\
\text { sentimentos de medo, desconforto e } \\
\text { vergonha. }\end{array}$ \\
\hline $\begin{array}{l}\text { Prevenção do } \\
\text { câncer de colo }\end{array}$ & 2008 & Ver. Rene & $\begin{array}{l}\text { O estudo teve por } \\
\text { objetivos verificar } \\
\text { percepções de mulheres }\end{array}$ & $\begin{array}{l}\text { Estudo descritivo- } \\
\text { exploratório realizado com } \\
34 \text { mulheres atendidas no }\end{array}$ & $\begin{array}{l}\text { organização das falas seguiu a } \\
\text { Técnica de Análise Categorial da } \\
\text { Análise de Conteúdo de Bardin. Os }\end{array}$ \\
\hline
\end{tabular}




\begin{tabular}{|c|c|c|c|}
\hline $\begin{array}{c}\text { uterino: } \\
\text { percepções de } \\
\text { mulheres ao } \\
\text { primeiro exame } \\
\text { e atitudes } \\
\text { profissionais }\end{array}$ & $\begin{array}{l}\text { com relação ao primeiro } \\
\text { exame de prevenção e } \\
\text { identificar atitudes } \\
\text { profissionais } \\
\text { favoráveis ao bem-estar } \\
\text { das mulheres na } \\
\text { realização do mesmo. }\end{array}$ & $\begin{array}{l}\text { Instituto de Prevenção do } \\
\text { Câncer do Ceará em março } \\
\text { e abril de } 2006 \text { e que } \\
\text { obedeceram aos critérios: } \\
\text { ter terminado de realizar o } \\
\text { primeiro e xame de } \\
\text { prevenção e aceitar } \\
\text { participar livremente do } \\
\text { estudo. }\end{array}$ & $\begin{array}{l}\text { sentimentos das mulheres foram } \\
\text { agrupados nas categorias vergonha; } \\
\text { medo; tensão, desconforto e dor; } \\
\text { "corpo de laboratório"; e } \\
\text { naturalidade. As atitudes profissionais } \\
\text { foram agrupadas em diálogo, toque, } \\
\text { paciência, acolhimento e aproximação } \\
\text { do universo cultural das mulheres. }\end{array}$ \\
\hline
\end{tabular}

Fonte: Autores (2021).

\section{Resultados e Discussão}

Objetivando resolver a problemática da pesquisa, variadas foram as bases utilizadas para que tais resoluções fossem pontuais e esclarecedoras, para tanto se faz necessário destacar importantes autores, como é o caso de Oliveira et. al., (2016) a autora destaca o perfil sociodemográfico das mulheres que realizam o exame Papanicolau bem como aborda quais as situações que impedem a procura para a realização do referido exame. Desse modo, destaca-se em seu trabalho três fatores principais, como sendo associados à não adesão ao exame, sendo a vergonha o primeiro motivo, seguida da ansiedade e posteriormente o tempo de espera necessário para obtenção do resultado.

Neves, et. al., (2016) apontam perspectiva que corrobora e fortalece a ideia da autora anterior, destacando que mesmo diante da necessidade da realização do exame Papanicolau para detecção precoce do câncer, a grande maioria das mulheres veem o exame como um procedimento extremamente invasivo, principalmente no que tange a exposição do corpo e permeia sobre sua sexualidade, de tal modo o procedimento acaba conferindo um sentimento negativo para a mulher que precisa realiza-lo.

Na pesquisa de Miranda, Rezende e Romero (2018), pesquisa essa realizada com 50 mulheres da área adstrita de uma Unidade Básica de Saúde, apenas $20 \%$ dessas afirmam que realizariam o exame pelas mãos de um profissional do sexo masculino, fator relatado por muitos outros autores como sendo inibitório para a realização do exame.

Ainda com base na pesquisa de Miranda; Rezende e Romero (2018) merecem destaque mais um fator, o não conhecimento por parte das mulheres sobre a devida importância que existe no exame Papanicolau, tendo sido expressamente debatido pelos autores, levantando então a importância do aconselhamento e orientação profissional, almejando a ruptura da problemática e enfatizando a necessidade da atividade do enfermeiro.

Brandão; Andrade e Olivindo (2020) destacam que a consulta de enfermagem é o momento mais adequado para o acolhimento e apoio a mulher que objetivo atendimento ginecológico, espaço onde o enfermeiro dever usar a educação em saúde como ferramenta de promoção da saúde, além de escuta qualificada para acolher as demandas da mulher, com foco na ruptura dos tabus, preconceitos, bem como no esclarecimento das dúvidas que circundam a conduta.

Segundo Silva et al (2014) o enfermeiro tem de apontar cada necessidade individual da mulher, precipuamente, aos sinais e sintomas, todavia o enfermeiro poderá depara-se com barreiras em relação ao entendimento sobre promoção a saúde e prevenção das doenças pelas mulheres como: ausência de informação, tabus da sexualidade.

O enfermeiro poderá elaborar orientações às mulheres acerca da prevenção do câncer de útero por meio de execução de palestras individuais ou em grupos, desse modo através dessas práticas as mulheres possam a entender qual o verdadeiro intuito do exame (Silva et al., 2014).

Segundo Sousa et al (2008) o profissional enfermeiro pode apresentar condutas e práticas para edulcorar sentimentos e percepções negativas das mulheres acerca do exame, denotando assim como sugestões para os profissionais que executam suas atividades nesta área do cuidado. Salientam-se também a comunicação, explanando para a paciente o procedimento, onde 
poderá levá-la a abstração, utilizando através do toque, acolhimento, paciência e estar sempre disposto a se aproximar do universo cultural feminino.

Alguns obstáculos podem surgir antes da realização do exame, como o medo e o constrangimento, como também o temor dos resultados, tais sentimentos anunciam as situações enfrentadas pela mulher por causa do exame Papanicolau. Desse modo, o exame acaba provocando aflições emocionais, porem essas aflições devem ser trabalhadas sempre antes da realização do exame pelo o enfermeiro (Moura et al., 2010).

Existe uma variedade de problemáticas envolvidas na não adesão da mulher ao exame preventivo, que segundo Cardoso et. al., (2020), está também atrelado ao fato das dificuldades encontradas para a realização do agendamento para a coleta, sendo então a acessibilidade uma problemática debatida entre os autores, em contra partida, Rodriguez \& Lemes (2016), consideram que existe uma barreira muito grande relação demanda e oferta dos serviços na atenção primária, de modo que pensar sobre essa resolução também se tornaria problemático.

Buscando romper com a problemática apresentada acima, ainda segundo a análise de Brandão; Andrade e Olivindo (2020), é importante que as unidades básicas de saúde façam o rastreamento das mulheres que residem na área, associando a isso a realização de atividades educativas, visto que é uma modalidade de cuidado facilmente aceita pelas mulheres, uma vez que essas buscam a redução de potenciais agravos, devendo ficar claro que mesmo que as mulheres conheçam a importância da realização do exame, nem sempre conhecem exatamente a gravidade do câncer do colo do útero.

Os autores Amaral, Gonçalves e Silveira (2017) acredita que é válido conhecer os motivos que influenciam a não adesão da mulher ao exame, avaliando esses fatores seria dado o primeiro passo para intervir adequadamente conforme as necessidades do público feminino acreditam-se firmemente também nas interferências que a cultura ocasiona, principalmente quando associada à exposição do corpo e somada à realização do exame pelo profissional do sexo masculino, questão já mencionada anteriormente no texto.

No estudo de Salimena et al (2014), encontra-se um analise importante para ser perpetuada pelos profissionais e serviços de saúde, uma vez que o estudo aponta o enfermeiro como sendo um profissional que trata bem a paciente e como profissional responsável pelo acolhimento e suporte emocional, fala oriunda das próprias entrevistadas, para tanto fica claro que os profissionais podem possuir comportamentos e atitudes como medidas para aplacar a percepção dos sentimentos negativos relatados e experiência dos pelas mulheres, ficando claro a importância do cuidado humanizado e da escuta qualificada, associados aos conhecimentos técnicos e científicos para o então fortalecimento do cuidado.

\section{Considerações Finais}

Ao analisar o objetivo proposto pelo material podem-se fazer as seguintes pontuações; o câncer do colo do útero é uma problemática que acomete um número significativo de mulheres em todo mundo, fazendo-se necessário a adoção de medidas preventivas e rastreio precoce, estando o exame Papanicolau considerado como padrão ouro na busca e rastreio do referido câncer.

No que concerne às problemáticas vivenciadas pelas mulheres, variados são os achados que apontam para a não adesão ao exame, merecendo destaque as crenças de exposição do corpo, o que é ainda mais difícil de fazer quando o exame é realizado por profissionais do sexo masculino. Vale destacar que mesmo quando a mulher se faz conhecedora da importância a realização do exame, fatores como medos e tabus acabam se tornando mais preponderantes que a busca pelo exame, é ainda observado que muitas são as mulheres que não possuem conhecimento sobre a agressividade e letalidade existente num diagnóstico de câncer do colo do útero.

Na perspectiva do profissional enfermeiro, este é visto como um ponto de apoio e fortalecimento do vinculo existente entre mulher e o serviço de saúde, podendo dessa relação surgir o fortalecimento necessário para o rompimento das barreiras 
encontradas pelas mulheres. O enfermeiro é responsável pela busca ativa, pela consulta de enfermagem e pela educação em saúde da população por ele assistida.

Fica evidente então que as barreiras encontradas pelas mulheres são muitas, porém não são incorrigíveis, uma vez que exista qualidade na abordagem profissional para com essas mulheres, podendo ser formulada uma nova forma de visualizar e aceitar a importância no rastreio e diagnóstico precoce que pode ser promovido pelo tão temido exame, Papanicolau.

Concisamente, diante do estudo envolvido, é preciso atinar e determinar novas pesquisas, essencialmente para abordar o enfermeiro na realização do exame de Papanicolau: Obstáculos e a percepção da mulher. Destarte, pesquisas futuras podem trazer reforços úteis para as evidências científicas, revelar inovações e cuidados atuais e ter como objetivo contribuir com a literatura científica e expandir novos conhecimentos.

\section{Referências}

Amaral, M. S., Gonçalves, A. G., \& Silveira, L. C. G. (2017). Prevenção do câncer de colo de útero: a atuação do profissional enfermeiro nas unidades básicas de saúde. Revista Científica FacMais, 8(1), 198-223.

Brandão, A. M. R., DE Andrade, F. W. R., \& De Olivindo, D. D. F. (2020). Atuação do enfermeiro da estratégia da saúde da família no manejo da mulher com resultado de colpocitologia alterado. Research, Society and Development, 9(10), e5899108962-e5899108962.

Cardoso, B. C. R. et al. (2020). Principais dificuldades para a realização do exame papanicolau em mulheres atendidas em uma unidade básica de saúde no bairro Jaderlândia, Ananindeua, estado do Pará. Brazilian Journal of Development, 6(3), 16007-16022.

Feitoza, D. et al. Epidemiologia do câncer de colo uterino no mundo e no Brasil.

Galvão, T. F., \& Pereira, M. G. (2014). Revisões sistemáticas da literatura: passos para sua elaboração. Epidemiologia e Serviços de Saúde, $23,183-184$.

Gonçalves, A. L., Ramalho, G. X., Muniz, G. G., Peixoto, H. M., \& Mascarenhas, F. A. N. (2020). Série de casos de mulheres com câncer de colo uterino em hospital público de Brasília. Brazilian Journal of Health Review, 3(3), 3920-3934.

Inca, Ministério da saúde. (2016). Diretrizes brasileiras para o rastreamento do câncer do colo do útero. (2a ed.), rev. Atual. INCA.

Miranda, A. P., Rezende, E. V., \& Romero, N. S. A. (2018). Percepção e adesão das mulheres quanto ao exame citopatológico. Nursing (Säo Paulo), 24352438 .

Moura, A. D. A. Conhecimento e motivações das mulheres acerca do exame de papanicolau: subsídios para a para a prática de enfermagem. (2010) Rev. Rene, Fortaleza, 11(1), 94-104.

Neves, K. T. Q. et al. (2016). Percepção de usuárias acerca do exame de detecção precoce do câncer de colo uterino. Cogitare Enfermagem, 21(4).

Oliveira, A. E. C. de et al. (2016). Adesão das mulheres ao exame citológico do colo uterino na atenção básica. Rev. enferm. UFPE on line, p. 4003-4014, 2016.

Rodrigues, J. Z., Schönholzer, T. E., \& Lemes, A. G. (2016). Perfil das mulheres que realizam o exame Papanicolau em uma estratégia de saúde da família. Journal of Nursing and Health, 6(3), 391-401.

Salimena, A. M. O. Oliveira, M. T. L., Paiva, A. C. P. C. et al. (2014). Mulheres portadoras de câncer de colo de útero: a percepção da assistência de enfermagem. R. Enferm. Cent. O. Min.

Santos, V. L. O. Rocha, J. M., Cunha, K. J. B. Câncer do colo do útero: desafios para o diagnóstico precoce/cervical cancer: challenges for early diagnosis. (2014). Saúde em Foco, 1(2), 60-71.

Silva, D. S. M. da et al. Rastreamento do câncer do colo do útero no Estado do Maranhão, Brasil. (2014). Ciência \& Saúde Coletiva, 19, 1163-1170.

Silveira, B. L. Câncer do colo do útero: papel do enfermeiro na estratégia e saúde da família. (2016). Monografia Faema - Faculdade de educação e meio ambiente. Curso de graduação em enfermagem.

SmieskiI, A. F., Dullius, J. L., \& Venazzi, C. B. (2018). Fatores associados a não realização do exame papanicolau segundo a percepção das mulheres atendidas na ubs dr. Carlos Scholtão município de Sinop/MT Factors associated with lack of papanicolau according to the perception of women seen at ubs Dr. Carlos Scholtão, Sinop/MT. Scientific Eletronic Archives, Mato Grosso, 11(2).

Sousa, I. G. da Silva et al. (2008). Prevenção do câncer de colo uterino: percepções de mulheres ao primeiro exame e atitudes profissionais. Rev Rene, 9(2), $38-46$.

Villani, M. S. (2012). O Exame Preventivo do Câncer Cérvico-Uterino na Visão De Mulheres Atendidas em Uma ESF. 2012. 22 f. Monografia (Especialização). Universidade Regional do Noroeste do Estado do Rio Grande do Sul (UNIJUÍ). 